\title{
Asthma in Greenwich, UK: impact of the disease and current management practices
}

\author{
G.B. Marks*, P.G.J. Burney*, U.N. Premaratne*, J. Simpson*, J. Webb**
}

Asthma in Greenwich, UK: impact of the disease and current management practices G.B. Marks, P.G.J. Burney, U.N. Premaratne, J. Simpson, J. Webb. @ERS Journals Ltd 1997

ABSTRACT: A great deal of the care of patients with asthma takes place in general practices. The aim of the present study was to describe the impact of asthma in the community and to identify current asthma self-management practices.

A two-part questionnaire survey was conducted in a random sample $(23 \%$; $n=$ 24,398) of persons aged 16-50 yrs, registered with one of the 41 general practices in Greenwich, London, UK. The two parts were: a screening questionnaire identifying persons with current asthma (defined as waking with shortness of breath in the last 12 months, attack of asthma in the last 12 months, or currently taking treatment for asthma); and an asthma questionnaire (completed by those with asthma) assessing quality of life, frequency of asthma symptoms, possession and use of self-management tools, and action in the event of an exacerbation of asthma. The crude response rate was $51 \%$, but this may be an underestimate due to errors in the sampling frame.

The prevalences of wheeze and asthma in the past 12 months were $26 \%$ and $14 \%$, respectively. Among asthma patients: $43 \%$ reported symptoms occurring three or more times per week, and $20 \%$ were woken by asthma symptoms on three or more nights per week; most had asthma with a mild impact on quality of life; $26 \%$ used inhaled steroids on most days in the preceding month; $16 \%$ had a peak flow meter at home; and $7 \%$ had oral steroids available. Of the $44 \%$ of subjects with asthma, who could identify an exacerbation of asthma in the preceding 6 months: $19 \%$ had used a peak flow meter during the episode; $19 \%$ had changed their treatment without first being told to do so by a doctor; and $50 \%$ had sought urgent medical help. Smokers used less appropriate asthma management and subjects whose asthma had a severe impact on quality of life used more treatment and peak flow monitoring.

In conclusion, the prevalence of asthma among adults in Greenwich, UK, has increased since a similar survey in 1986. Many people have fairly mild asthma and a smaller number have severe disease. Much remains to be done to promote appropriate strategies for self-management of asthma exacerbations.

Eur Respir J 1997; 10: 1224-1229.
*Dept of Public Health Medicine, United Medical and Dental Schools of Guy's and St Thomas' Hospitals, London, UK. **Greenwich District Hospital, London, UK.

Correspondence: G.B. Marks

Chest Clinic

Level 3, Health Services Building Liverpool Hospital

PO Box 103

Liverpool NSW 2170

Australia

Keywords: General practice

quality of life

self-management

Received: January 221996

Accepted after revision January 311997

This study was funded by a project grant from the Medical Research Council of the United Kingdom. During the course of this study, GBM was the recipient of the Cottrell Fellowship from the Royal Australasian College of Physicians and a travelling fellowship from the Asthma Foundation of New South Wales. He also received assistance from Sydney Hospitallers (Norman Rose Travelling Grant) and the Asthma Foundation of Victoria (Lillian Roxon Memorial Foundation).
Asthma is a prevalent chronic disease causing substantial disability and some mortality in many countries across a wide range of ages [1-6]. Advances in the understanding of the pathology of asthma have been accompanied by a widely held view that a systematic approach is required to control this disease. The recommended approach has been embodied in a number of consensus documents outlining guidelines for the management of chronic asthma [7-10].

The nature of asthma and its prevalence means that, in the UK, a great deal of the care of patients with asthma takes place in general practices. One of the implications of the British Thoracic Society (BTS) guidelines [10] is that this care should be enhanced by the implementation of protocols for the management of patients with asthma.

There have been substantial developments in the management of asthma in general practice [10], and in shared care between hospitals and general practices [11]. There have also been important changes to general practice funding, which have tended to promote asthma clinics in this setting [12]. However, there has not yet been a controlled evaluation of the value of general practicebased asthma clinics undertaking care along the lines advised in the BTS guidelines.

We have commenced a randomized, controlled trial of an intervention to facilitate guidelines-based management of asthma in general practice asthma clinics. The trial is being conducted in Greenwich, an area of southeast London, UK, with rates of adult male unemployment (14\%), public housing tenancies (38\%), and chronic illness $(13 \%)$ higher than the average for Greater London [13].

In the course of this evaluation, we undertook a crosssectional survey at baseline to describe the impact of asthma in the community and to identify current asthma self-management practices and the factors that influence them. These data are presented in this paper. We believe 
they provide a valuable representation of asthma in one community in the UK.

\section{Methods}

A postal questionnaire survey was conducted to collect baseline data for the controlled trial of a general practice-based asthma care intervention. A random population sample received a single questionnaire made up of two parts. All subjects were asked to complete the initial screening part of the questionnaire. Subjects identified by the screening questionnaire as having asthma were then asked to complete the second part.

The study was approved by the Greenwich District Research Ethics Committee.

\section{Sample selection}

The study population for the questionnaire survey was those persons, aged $16-50$ yrs, who were registered with any of the 41 general practices in Greenwich district. The lower age limit was chosen because the intervention was primarily directed at adults with asthma. The upper age limit was chosen because above this age it becomes more difficult to distinguish between asthma and chronic obstructive pulmonary disease (COPD) by questionnaire.

Data on the study population were obtained from the Greenwich and Bexley Family Health Services Authority (FHSA). All people in the UK who seek medical care are required to register with a general practitioner (GP). This information is conveyed to a FHSA, which keeps records of the names, addresses, and National Health Service (NHS) numbers of patients registered with each GP. This information is updated when patients notify their GP of a change in address or when they register with another GP.

The study population comprised 106,086 people. A $23 \%$ random sample, stratified by general practice, was drawn, yielding a sample size of 24,398 subjects. The sample size was chosen to provide sufficient power for the analysis of the randomized, controlled trial.

\section{Questionnaire}

The first part of the questionnaire was a screening questionnaire identical to that used in the European Community Respiratory Health Survey [14, 15]. Subjects who answered "Yes" to any one of the following three questions were defined as having asthma: 1) "Have you been woken up by an attack of shortness of breath at any time in the last 12 months?"; 2) "Have you had an attack of asthma in the last 12 months?"; and 3) "Are you currently taking any medicine (including inhalers, aerosols or tablets) for asthma?"

Subjects who were deemed to have asthma were requested to complete the second part of the questionnaire: the asthma questionnaire. This comprised a previously developed asthma quality of life questionnaire [16, 17], and new items dealing with symptom frequency, disability, current asthma management, and stated response to the most recent exacerbation of asthma.
The asthma quality of life questionnaire contains 20 items and deals with breathlessness and physical restrictions, mood disturbance, social disruption, and concerns for health over the preceding month. Each item is associated with a five-point Likert scale response: "not at all"; "mildly"; "moderately"; "severely"; and "very severely". The questionnaire is scored by averaging the item scores (0 to 4$)$ over all 20 items. The result is multiplied by 2.5 to yield a final score out of 10: 0 corresponding to no impact on quality of life and 10 corresponding to very severe impact on quality of life.

A subset of subjects with asthma who were able to recognize a recent exacerbation of asthma were identified by a positive response to the following question: "Over the last 6 months have you had any episodes lasting a few days or weeks during which your asthma or shortness of breath was worse than usual for you?" These subjects were asked further questions about their response to this episode: use of a peak flow meter; alterations to treatment; and seeking emergency medical help.

The new items in the asthma questionnaire were pilot tested for feasibility in a sample of 16 patients with asthma attending a respiratory medicine out-patients clinic. The screening questionnaire took approximately $2-3 \mathrm{~min}$ to complete. The asthma questionnaire took approximately $10-15 \mathrm{~min}$ to complete.

\section{Survey methodology}

The survey commenced in September, 1993. The questionnaire was posted to each subject and was accompanied by a letter explaining the survey and requesting their co-operation. This letter was signed by all the partners of the general practice with which the subject was registered. Subjects were asked to return the completed questionnaire in an enclosed reply-paid envelope. Subjects who had not responded within 4 weeks of the initial mailshot were sent another identical letter and questionnaire at that time. A third, and final mailshot was issued to nonresponders after a further 4 weeks. The survey was closed 4 weeks after that, in December, 1993.

\section{Survey of nonresponders}

A survey of nonresponders was conducted to assess the accuracy of the FHSA's patient register, which had been used to select the survey sample. A random sample of 190 subjects was drawn from the list of those who had not responded at the close of the survey. Fieldworkers visited the listed addresses of these subjects to ascertain whether the subject actually lived at that address (or had done during the survey period).

\section{Statistical analysis}

Univariate comparisons between proportions were tested by the Chi-squared test. Multivariable logistic regression was used to estimate odds ratios (ORs) for predictor variables, adjusted for other predictors and for potential confounders. A p-value of 0.05 was regarded as significant. 


\section{Results}

Response rate and survey of nonresponders

The total number of valid responses was 12,545, which comprised 8,887 (71\%) after the first mailing, 2,359 (19\%) after the second mailing, and 1,299 (10\%) after the third mailing. The response rate was $51 \%$. An additional 650 questionnaires $(5 \%)$ were returned with information that the respondent did not live at the nominated address.

Of 190 subjects in the survey of nonresponders, 60 could not be accounted for, 61 were confirmed as living at the registered address, and a further 11 were living at the address at some time during the survey period. Fifty eight were not living at the address during the survey. Assuming all those who could not be accounted for did live at their registered address, we estimate that in $30 \%$ of cases of nonresponse the subject was not living at the address listed on our register. This means that an estimated $15 \%$ of the total sample were incorrectly registered. If the denominator in the response rate calculation is reduced by this number, the adjusted response rate becomes $60 \%$. If the 60 subjects who could not be accounted for did not live at the address shown in the register, the estimated total incorrect address rate becomes $30 \%$ and the adjusted response rate becomes $74 \%$.

Screening questionnaire: prevalence of symptoms and of asthma

The mean age of respondents was 33 yrs, $56 \%$ were females and $44 \%$ males, $46 \%$ had smoked more than one cigarette day $^{-1}$ for a year or more, and $36 \%$ were current smokers (in the last month).

Table 1 shows that $26 \%$ of respondents reported wheezing in the preceding 12 months. This included 13\% in whom the wheeze occurred without colds and was associated with breathlessness. This history of wheeze was more common in females than males (14 vs $12 \%$; $\mathrm{p}=0.002$ by Chi-squared test). The prevalence of asthma, defined as having been woken up by shortness of breath in the last 12 months, having had an attack of

Table 1. - Prevalence (\%) of symptoms and of asthma in the last 12 months

\begin{tabular}{lrrrl}
\hline & $\begin{array}{c}\text { All } \\
\text { subj. } \\
\%\end{array}$ & M & F & $\begin{array}{c}\text { p- } \\
\text { value* }\end{array}$ \\
& \multicolumn{1}{c}{$\%$} & \\
\hline Wheezing/whistling in chest & 26.1 & 25.6 & 26.4 & 0.35 \\
Breathless with wheezing & 15.8 & 14.4 & 17.1 & 0.001 \\
Wheezing without colds & 19.3 & 19.5 & 19.3 & 0.81 \\
Woken by tightness in chest & 19.2 & 18.7 & 19.6 & 0.21 \\
Woken by shortness of breath & 8.9 & 8.4 & 9.2 & 0.11 \\
$\begin{array}{l}\text { Woken by coughing } \\
\text { Asthma attack }\end{array}$ & 29.3 & 23.5 & 34.0 & 0.001 \\
$\begin{array}{l}\text { Currently taking medicine } \\
\text { for asthma }\end{array}$ & 6.4 & 5.5 & 7.1 & 0.001 \\
$\begin{array}{l}\text { Nasal allergies including } \\
\text { hay fever }\end{array}$ & 8.6 & 7.9 & 9.2 & 0.011 \\
\hline
\end{tabular}

*: comparison of proportions in males and females (Chi-squared test). F: female; M: male; subj.: subjects. asthma in the last 12 months, or currently taking medicine for asthma, was $14 \%$. The prevalence of asthma was higher in females than males (14 versus $13 \%$; $\mathrm{p}=$ $0.016)$. The prevalence of asthma did not vary between those who responded early or late to the survey $(13.5 \%$ for first mailing, $14 \%$ for second mailing, $13 \%$ for final mailing; $\mathrm{p}=0.7$ ).

The remainder of the results presented here refer to those subjects with asthma who completed the asthma questionnaire. The screening questionnaire identified 1,676 subjects as having asthma and, therefore, being eligible to complete the asthma questionnaire. Of these, $1,641(98 \%)$ answered at least one question from the asthma questionnaire. The response rate for individual questions within the asthma questionnaire ranged 87$94 \%$. Quality of life scale scores could be calculated for 1,582 subjects $(94 \%)$.

\section{Impact of asthma in patients with the disease}

Among patients with asthma, $43 \%$ reported symptoms occurring three or more times per week and $20 \%$ were woken by asthma symptoms on three or more nights per week (table 2).

The proportion of subjects with asthma who, in the preceding 6 months, had at some time been unable to go to work or carry out their usual daily activities because of asthma was $24 \%$. Among these subjects, the median number of days of disablement over this period was six.

The distribution of asthma quality of life scores is unimodal and skewed, with a median score of 2 and an interquartile range of 1.1-3.5 (fig. 1). This indicates that

Table 2. - Symptom frequency in subjects with asthma in the last month

\begin{tabular}{lcc}
\hline & $\begin{array}{c}\text { Any } \\
\text { symptoms } \\
\%\end{array}$ & $\begin{array}{c}\text { Woken by } \\
\text { symptoms } \\
\%\end{array}$ \\
\hline Every day & 16 & 4 \\
Three or more times a week & 27 & 16 \\
One or more times a month & 40 & 39 \\
Not at all & 17 & 41 \\
\hline
\end{tabular}

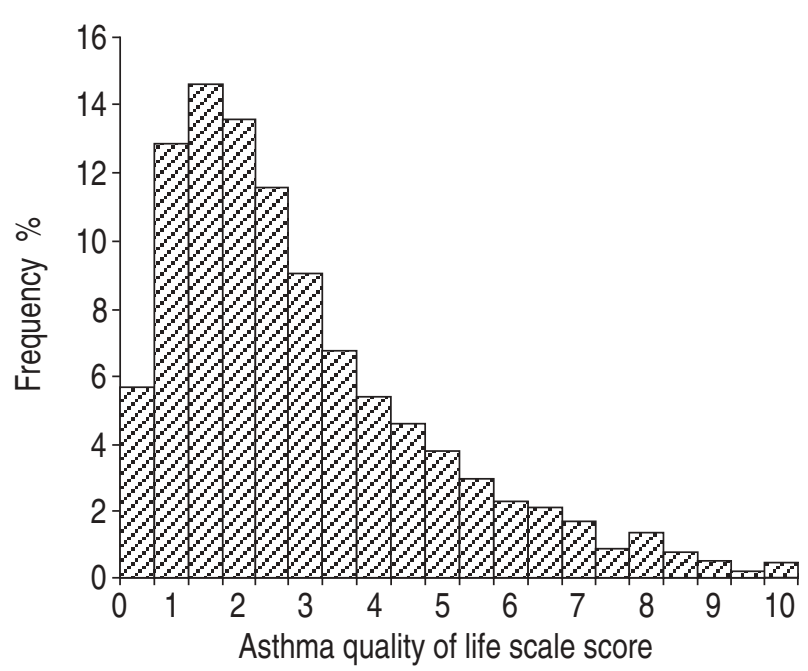

Fig. 1. - Frequency histogram of the distribution of asthma quality of life scale scores (out of 10) in the subjects with asthma $(n=1,582)$. 
most subjects reported that asthma had a mild impact on their quality of life. People with more frequent asthma symptoms had worse scores on the asthma quality of life scale. Forty six per cent of people with asthma symptoms on three or more days per week had asthma quality of life scores above 3.5 (that is, in the worst quartile). In comparison, $12 \%$ of people with less frequent symptoms had quality of life scores in the worst quartile $(\mathrm{p}<0.001)$. Similarly, $58 \%$ of those woken by asthma symptoms three or more times per week had quality of life scores in the worst quartile, compared to $18 \%$ of those woken less frequently $(\mathrm{p}<0.001)$.

The independent effects of personal characteristics and symptom frequency on the quality of life scale score were investigated in a logistic regression analysis (table 3 ). After adjustment for the increased proportion of older

Table 3. - Factors predicting asthma quality of life scores in the worst quartile of the distribution $(>3.5)$

\begin{tabular}{lcc}
\hline & $\mathrm{OR}^{*}$ & $95 \%$ CI \\
\hline Female gender & 1.18 & $0.91-1.53$ \\
Age (per 5 yrs) & 1.10 & $1.03-1.18$ \\
Current smoker & 1.28 & $0.99-1.66$ \\
$\quad$ Experienced asthma symptoms & 4.28 & $3.19-5.75$ \\
$\quad$ 23 times per week & & \\
Woken by asthma symptoms & 2.70 & $1.99-3.68$ \\
$\quad \geq 3$ times per week & &
\end{tabular}

*: estimated by multivariate logistic regression analysis. Odds ratios are adjusted for the other terms in the model $(n=1,510)$. OR: odds ratio; $95 \% \mathrm{CI}$ : $95 \%$ confidence interval. subjects and smokers with quality of life scores in the worst quartile, both frequent symptoms and frequent nocturnal symptoms independently predicted a poor asthma quality of life score.

\section{Asthma self-management tools and practices}

Although $37 \%$ of subjects had a steroid inhaler at home, only $71 \%$ of these $(26 \%$ of subjects with asthma) stated that they had used it on most days in the preceding month. Only $16 \%$ of subjects had a peak flow meter at home, and only $8 \%$ said they had used it in the last month. Very few subjects (7\%) had a supply of steroid tablets in the house.

Of $744(44 \%)$ subjects who could identify an exacerbation of asthma within the preceding 6 months, 19\% had used a peak flow meter during the episode, $19 \%$ had changed their treatment without first being told to do so by a doctor, and $50 \%$ had sought urgent medical help from their GP or an Accident and Emergency Department.

Factors influencing self-management practices are shown in tables 4 and 5. Older subjects were less likely to have inhaled steroids and more likely to have oral steroids at home. They showed a greater propensity than younger subjects to seek medical help for an exacerbation of asthma. Possession of self-management tools and self-management behaviour was unrelated to gender. Current smokers were less likely than nonsmokers to have and to use inhaled steroids or peak flow meters

Table 4. - Factors influencing self-management tools

\begin{tabular}{|c|c|c|c|c|c|c|}
\hline & $\begin{array}{c}\text { Age } \\
\text { per } 5 \text { yrs }\end{array}$ & $\begin{array}{l}\text { Female } \\
\text { gender }\end{array}$ & $\begin{array}{l}\text { Current } \\
\text { smoker }\end{array}$ & $\begin{array}{l}\text { Frequent } \\
\text { symptoms* }\end{array}$ & $\begin{array}{l}\text { Frequent } \\
\text { waking }^{+}\end{array}$ & $\begin{array}{c}\text { Worse } \\
\text { QOL score }\end{array}$ \\
\hline $\begin{array}{l}\text { Steroid inhaler at home } \\
(\mathrm{n}=619 / 1,409)^{\$}\end{array}$ & $\begin{array}{c}0.92 \\
(0.87-0.98)\end{array}$ & $\begin{array}{c}1.22 \\
(0.94-1.07)\end{array}$ & $\begin{array}{c}0.66 \\
(0.52-0.83)\end{array}$ & $\begin{array}{c}1.75 \\
(1.34-2.29)\end{array}$ & $\begin{array}{c}1.26 \\
(0.91-1.75)\end{array}$ & $\begin{array}{c}2.93 \\
(2.22-3.87)\end{array}$ \\
\hline $\begin{array}{l}\text { Use steroid inhaler most days } \\
(\mathrm{n}=442 / 1,442)^{\$}\end{array}$ & $\begin{array}{c}1.00 \\
(0.94-1.07)\end{array}$ & $\begin{array}{c}1.08 \\
(0.84-1.38)\end{array}$ & $\begin{array}{c}0.68 \\
(0.53-0.88)\end{array}$ & $\begin{array}{c}2.17 \\
(1.63-2.90)\end{array}$ & $\begin{array}{c}1.56 \\
(1.13-2.15)\end{array}$ & $\begin{array}{c}3.20 \\
(2.42-4.23)\end{array}$ \\
\hline Own a PFM & 0.97 & $\begin{array}{l}1.15 \\
(087\end{array}$ & 0.51 & 1.70 & $\begin{array}{c}1.09 \\
(0.157)\end{array}$ & 2.31 \\
\hline $\begin{array}{l}\text { Used a PFM in last month } \\
(\mathrm{n}=131 / 1,434)^{\$}\end{array}$ & $\begin{array}{c}1.01 \\
(0.91-1.12)\end{array}$ & $\begin{array}{c}1.24 \\
(0.84-1.83)\end{array}$ & $\begin{array}{c}0.68 \\
(0.46-1.02)\end{array}$ & $\begin{array}{c}1.15 \\
(0.71-1.84)\end{array}$ & $\begin{array}{c}1.42 \\
(0.88-2.30)\end{array}$ & $\begin{array}{c}3.34 \\
(2.18-5.11)\end{array}$ \\
\hline $\begin{array}{l}\text { Oral steroids at home } \\
(\mathrm{n}=112 / 1,457)^{\$}\end{array}$ & $\begin{array}{c}1.13 \\
(1.01-1.26)\end{array}$ & $\begin{array}{c}1.20 \\
(0.79-1.83)\end{array}$ & $\begin{array}{c}0.91 \\
(0.60-1.39)\end{array}$ & $\begin{array}{c}1.30 \\
(0.76-2.25)\end{array}$ & $\begin{array}{c}2.51 \\
(1.51-4.18)\end{array}$ & $\begin{array}{c}2.60 \\
(1.65-4.10)\end{array}$ \\
\hline
\end{tabular}

Odds ratios (and 95\% CI in parenthesis) estimated by logistic regression are presented, with adjustment for all other independent variables in the table. Values where $95 \%$ CI excludes one are presented in bold. *: experienced asthma symptoms $\geq 3$ times per week; +: awoken by asthma symptoms $\geq 3$ times per week; \#: asthma quality of life (QOL) score $>3.5$ (i.e. in the worst quartile); \$: number of subjects with the self-management tool/number of observations available for analysis. PFM: peak flow meter; 95\% CI: $95 \%$ confidence interval.

Table 5. - Factors influencing self-management of exacerbations

\begin{tabular}{lcccccc}
\hline & $\begin{array}{c}\text { Age } \\
\text { per 5 yrs }\end{array}$ & $\begin{array}{c}\text { Female } \\
\text { gender }\end{array}$ & $\begin{array}{c}\text { Current } \\
\text { smoker }\end{array}$ & $\begin{array}{c}\text { Frequent } \\
\text { symptoms* }\end{array}$ & $\begin{array}{c}\text { Frequent } \\
\text { waking }^{+}\end{array}$ & $\begin{array}{c}\text { Worse } \\
\text { QOL score }\end{array}$ \\
\hline Used peak flow meter & 1.03 & 1.32 & $\mathbf{0 . 6 0}$ & 0.81 & 1.20 & $\mathbf{2 . 1 8}$ \\
$(\mathrm{n}=139 / 684)^{\$}$ & $(0.92-1.14)$ & $(0.88-1.99)$ & $\mathbf{( 0 . 3 9 - 0 . 9 0 )}$ & $(0.51-1.29)$ & $(0.75-1.94)$ & $\mathbf{( 1 . 4 2 - 3 . 3 5 )}$ \\
Changed own treatment & 0.96 & 1.36 & $\mathbf{0 . 6 4}$ & $\mathbf{1 . 9 9}$ & 0.88 & 1.21 \\
$(\mathrm{n}=140 / 690)^{\$}$ & $(0.87-1.07)$ & $(0.91-2.04)$ & $\mathbf{( 0 . 4 2 - 0 . 9 6 )}$ & $\mathbf{( 1 . 2 5 - 3 . 1 7 )}$ & $(0.55-1.39)$ & $(0.80-1.84)$ \\
$\begin{array}{l}\text { Sought urgent medical help } \\
(\mathrm{n}=368 / 696)^{\$}\end{array}$ & $\mathbf{1 . 1 0}$ & 1.05 & 0.98 & 0.75 & 1.42 & $\mathbf{1 . 9 3}$ \\
\hline
\end{tabular}

Odds ratios (and 95\% CI in parenthesis) estimated by logistic regression are presented, with adjustment for all other independent variables in the table. Values where $95 \%$ CI excludes one are presented in bold. *: experienced asthma symptoms $\geq 3$ times per week; +: awoken by asthma symptoms $\geq 3$ times per week; \#: asthma quality of life (QOL) score $>3.5$ (i.e. in the worst quartile); \$: number of subjects reporting this action/number of observations available for analysis. $95 \%$ CI: $95 \%$ confidence interval. 
and, during an exacerbation of their illness, showed less willingness to alter their own treatment.

As expected, subjects with more frequent asthma symptoms used more inhaled steroids and more commonly owned a peak flow meter compared to those with less frequent symptoms (table 4). Possession of oral steroids was particularly related to nocturnal symptoms. Subjects who perceived that asthma had a major impact on their quality of life were much more likely to have and to use inhaled steroids and peak flow meters and to keep oral steroids in the home (table 4). They also showed a stronger tendency to measure their peak flow during an exacerbation compared to those with better quality of life scores (table 5). This strong relationship between perceived quality of life and self-management practices was apparent after adjustment for symptom frequency (tables 4 and 5).

\section{Discussion}

This survey of the impact of asthma in adults living in Greenwich, southeast London, UK, has confirmed that this is a prevalent chronic disease in this setting. As expected, subjects identified in a random population survey cover a wide spectrum of disease severity: predominantly mild but including some with severe disease. Many patients do not have self-management tools at home, including a substantial proportion of those with severe disease. Few patients say that they measured their peak flow rate or adjusted their own medication during their most recent exacerbation of asthma. There is a strong relationship between perceived quality of life and self-management practices, and this is independent of disease severity as judged by frequency of asthma symptoms.

The response rate in this questionnaire survey was low. The survey of nonresponders demonstrates this was, in part, due to the highly mobile nature of this urban population. The extent to which the low response rate was due to inaccuracy of the practice lists, reduces the potential for selection bias in the results. A survey of nonresponders in a similar study of asthma in three East Anglian towns demonstrated that nonresponse bias did not have any substantial impact on the estimates of prevalence [18]. In this study, the absence of any trend in prevalence between the early and late responders also supports the contention that selection bias is unlikely to have an important influence on the conclusions. The high response rate for the asthma questionnaire among those found to have asthma means that bias in the results of this questionnaire should not be a problem.

The estimates for the prevalence of asthma in this population are very similar to those reported recently, using an identical questionnaire, in subjects aged 20-44 yrs in three towns in East Anglia, UK [18]. In contrast, a survey of males aged 20-44 yrs, selected at random from the electoral register and living in the Greenwich local authority district in 1986, found a prevalence of asthma-like symptoms that was less than half that in the current study: $12.2 \%$ reported wheeze in the last 12 months and $3.9 \%$ were woken by breathlessness [5]. In that survey, the question on wheeze was identical to the current study. The other question was very similar: "Have you, at any time in the last 12 months, been woken at night by an attack of shortness of breath?" It seems unlikely that such a large change in prevalence can be attributed to these minor methodological differences.

Inhaled steroids are now widely-used in patients in this community: nearly four out of 10 subjects with asthma and $60 \%$ of those with more severe asthma were prescribed them. This proportion is consistent with the $32 \%$ of adults with asthma, identified by a record review in a general practice in inner London, UK, who were receiving inhaled steroids [19]. It is also similar to the finding among general practices in the Northern region of England, where $35-40 \%$ of young adults diagnosed with asthma were prescribed inhaled steroids [20]. It represents a substantial increase on the $15 \%$ of males with night-time breathlessness, who were receiving inhaled steroids in 1986 [5]. It would not be wise to speculate on the appropriateness of this prescription based on the data available. It is noteworthy that nearly a third of those who had inhaled steroids at home were not using the drug regularly.

Peak flow meters are not widely available in the homes of patients with asthma: consequently, few subjects made objective measurements during exacerbations. Less than one in five subjects made any self-initiated change in their treatment during an exacerbation. We do not know what changes these subjects made: some will simply have increased inhaled bronchodilators, while others will have started or increased oral or inhaled steroids. The most common action in the face of an exacerbation remains the decision to seek urgent medical attention. There is room for improvement here: provision of self-management tools with appropriate education and written action plans may lead to early patient-initiated action to treat exacerbations and avoid the need for urgent medical attention.

There is a low rate of possession and use of selfmanagement tools among current smokers. It is possible that some of these people have COPD rather than asthma. However, the upper age limit of 50 yrs will have excluded most subjects with symptomatic COPD. Two explanations seem more plausible: firstly, that smokers exhibit behavioural traits that mitigate against appropriate self-management practices; and, secondly, that doctors have a nihilistic attitude towards airways disease in smokers. This finding implies that more attention should be paid to the management of asthma in smokers.

The asthma quality of life scale was a stronger predictor of self-management practices than simple questions about the frequency of asthma symptoms. This is because the quality of life questionnaire measures the impact of asthma in a more holistic manner [21]. Those who perceive a major impact of asthma are more likely to induce their medical attendants to prescribe inhaled and oral steroids. It has previously been shown that patients with high levels of anxiety induce more oral steroid prescriptions from their physicians [22]. Although patients with poor quality of life due to asthma do take more inhaled steroids and do measure their peak flow rates more appropriately, they still respond to exacerbations by seeking urgent medical attention more frequently than others. They are not more likely than others to self-initiate treatment changes during disease exacerbations. 
The patient and the medical attendant may both have a role in this hesitancy.

This cross-sectional survey of asthma in Greenwich, $\mathrm{UK}$, has revealed a marked increase in the prevalence of this disease among adults since 1986 . We have shown that some, mainly pharmaceutical, messages about modern asthma management have been widely adopted: inhaled steroids are relatively commonly prescribed to patients with asthma. On the other hand, much remains to be done to promote appropriate strategies for selfmanagement of asthma exacerbations. Smokers should be targeted for improved asthma management, as well as for smoking cessation interventions.

Acknowledgements: The authors are grateful to the Greenwich and Bexley Family Health Services Authority for their support and for providing the practice lists. The postal survey was conducted to the authors specifications by Taylor Nelson Health Care plc. The authors wish to acknowledge the assistance of their field-workers F. Beveney and S. Malwah, and statistical assistance from R. Dundas.

\section{References}

1. Leung R, Ho P. Asthma, allergy, and atopy in three south-east Asian populations. Thorax 1994; 49: 1205 1210.

2. Lange P, Ulrik CS, Vestbo J, for the Copenhagen City Heart Study Group. Mortality in adults with self-reported asthma. Lancet 1996; 347: 1285-1289.

3. von Mutius E, Martinez FD, Fritzsch C, Nicolai T, Roell $\mathrm{G}$, Thiemann $\mathrm{H}-\mathrm{H}$. Prevalence of asthma and atopy in two areas of West and East Germany. Am J Respir Crit Care Med 1994; 149: 358-364.

4. Strachan DP, Anderson HR, Limb ES, O'Neill A, Wells N. A national survey of asthma prevalence, severity, and treatment in Great Britain. Arch Dis Child 1994; 70: 174-178.

5. Burney PGJ, Papacosta AO, Withey $\mathrm{CH}$, Colley JRT, Holland WW. Hospital admission rates and the prevalence of asthma symptoms in 20 local authority districts. Thorax 1991; 46: 574-579.

6. Pearce N, Weiland S, Keil U, et al. Self-reported prevalence of asthma symptoms in children in Australia, England, Germany and New Zealand: an international comparison using the ISAAC protocol. Eur Respir $J$ 1993; 6: 1455-1461.

7. Woolcock AJ, Rubinfeld AR, Seale JP. Asthma management plan. Med J Aust 1989; 151: 650-653.
8. British Thoracic Society, Research Unit of the Royal College of Physicians of London, King's Fund Centre, National Asthma Campaign. Guidelines for management of asthma. I. Chronic persistent asthma. BMJ 1990; 301: 651-653.

9. National Heart Lung, and Blood Institute, National Institutes for Health. International consensus report on diagnosis and treatment of asthma. Eur Respir J 1992; 5: 601-641.

10. British Thoracic Society and others. Guidelines for the management of asthma: a summary. BMJ 1993; 306: 776-782.

11. Drummond N, Abdalla M, Buckingham JK, et al. Integrated care for asthma: a clinical, social, and economic evaluation. BMJ 1994; 308: 559-564.

12. Department of Health and Welsh Office. General practice in the National Health Service: a new contract. London, Her Majesty's Stationary Office, 1989.

13. Office of Population Censuses and Surveys (UK). Small area statistics, 1991 census. London, HMSO, 1991.

14. Burney P, Chinn S. Developing a new questionnaire for measuring the prevalence and distribution of asthma. Chest 1987; 91: 79s-83s.

15. Burney PGJ, Luczynska C, Chinn S, Jarvis D, for the European Community Respiratory Health Survey. The European Community Respiratory Health Survey. Eur Respir J 1994; 7: 954-960.

16. Marks G, Dunn S, Woolcock AJ. A scale for the measurement of quality of life in adults with asthma. J Clin Epidemiol 1992; 45: 461-472.

17. Marks GB, Dunn SM, Woolcock AJ. An evaluation of an asthma quality of life questionnaire as a measure of change in adults with asthma. J Clin Epidemiol 1993; 46: 1103-1111.

18. Jarvis D, Lai E, Luczynska C, Chinn S, Burney P. Prevalence of asthma and asthma-like symptoms in young adults living in three East Anglian towns. $\mathrm{Br} \mathrm{J} \mathrm{Gen}$ Pract 1994; 44: 493-497.

19. Gellert AR, Gellert SL, Iliffe SR. Prevalence and management of asthma in a London inner city general practice. Br J Gen Pract 1990; 40: 197-201.

20. Roberts SJ, Bateman DN. Which patients are prescribed inhaled antiasthma drugs? Thorax 1994; 49: 1090-1095.

21. Spitzer WO. State of science 1986: quality of life and functional status as a target variable for research. $J$ Chron Dis 1987; 40: 459-463.

22. Dirks JF, Horton DJ, Kinsman RA, Fross KH, Jones NF. Patient and physician characteristics influencing medical decisions in asthma. J Asthma Res 1978; 15: 171-178. 